\title{
Pulmonary Arterial Dilatation: Imaging Evaluation Using Multidetector Computed Tomography
}

\author{
Sreenivasa Narayana Raju ${ }^{1, \#} \quad$ Niraj Nirmal Pandey ${ }^{1, *, \odot}$ Arun Sharma ${ }^{1, \odot} \quad$ Amarinder Singh Malhi ${ }^{1}$ \\ Siddharthan Deepti², Sanjeev Kumar ${ }^{1}$
}

${ }^{1}$ Department of Cardiovascular Radiology and Endovascular Interventions, All India Institute of Medical Sciences, New Delhi, India

2Department of Cardiology, All India Institute of Medical Sciences, New Delhi India

\begin{abstract}
Address for correspondence Dr. Arun Sharma, DM, 148, Lane no. 2, The Foothills, Mullanpur (PB) 140901, India (e-mail: drarungautam@gmail.com).
\end{abstract}

Indian J Radiol Imaging 2021;31:409-420.

\begin{abstract}
Keywords

- pulmonary artery dilatation

- pulmonary arterial hypertension

- cardiac shunt

- vasculitis

- pulmonary thromboembolism

Pulmonary artery dilatation comprises a heterogeneous group of disorders. Early diagnosis is important as the presentation may be incidental, chronic, or acute and life threatening depending upon the etiology. Cross-sectional imaging plays an important role, with $\mathrm{CT}$ pulmonary angiography being regarded as the first line investigation in the evaluation of pulmonary artery pathologies. Moreover, effects of pulmonary artery lesions on proximal and distal circulation can also be ascertained with the detection of associated conditions. Special attention should also be given to the left main coronary artery and the trachea-bronchial tree as they may be extrinsically compressed by the dilated pulmonary artery. In context of an appropriate clinical background, CT pulmonary angiography also helps in treatment planning, prognostication, and follow-up of these patients. This review mainly deals with imaging evaluation of the pulmonary arterial dilatations on $\mathrm{CT}$ with emphasis on the gamut of etiologies in the adult as well as pediatric populations.
\end{abstract}

\section{Introduction}

Pulmonary artery dilatation is a relatively common concern for the practicing physician when it is usually detected on plain radiograph either incidentally or in patients with respiratory symptoms. Although chest X-ray is the initial imaging modality to detect pulmonary artery dilatation, cross sectional imaging allows for accurate assessment without superimposition of hilar and mediastinal structures. The current state-of-the-art multidetector computed tomography (CT) scanners with noninvasive CT pulmonary angiography provide precise evaluation of the pulmonary arteries and their branches with an additional advantage of simultaneous assessment of the lung parenchyma which is not possible on invasive angiography. In this article, we review the CT angiographic evaluation of the dilative lesions of the pulmonary artery per se with an emphasis on the etiology of the spectrum of these lesions in the adult and pediatric population so as to provide a comprehensive assessment of dilated pulmonary arteries in all age groups. -Figs. 1 and 2 depict the algorithmic approach to the etiological diagnosis of pulmonary artery dilatation on multidetector $\mathrm{CT}$ angiography in the pediatric and adult population, respectively.

*Sreenivasa Narayana Raju and Niraj Nirmal Pandey contributed equally to the manuscript and share the first authorship.

published online

August 4, 2021
DOI https://doi.org/

$10.1055 / \mathrm{s}-0041-1734225$ ISSN 0971-3026
(C) 2021. Indian Radiological Association.

This is an open access article published by Thieme under the terms of the Creative Commons Attribution-NonDerivative-NonCommercial-License, permitting copying and reproduction so long as the original work is given appropriate credit. Contents may not be used for commercial purposes, or adapted, remixed, transformed or built upon. (https://creativecommons.org/licenses/by-nc-nd/4.0/).

Thieme Medical and Scientific Publishers Private Ltd. A-12, Second Floor, Sector -2, NOIDA -201301, India 


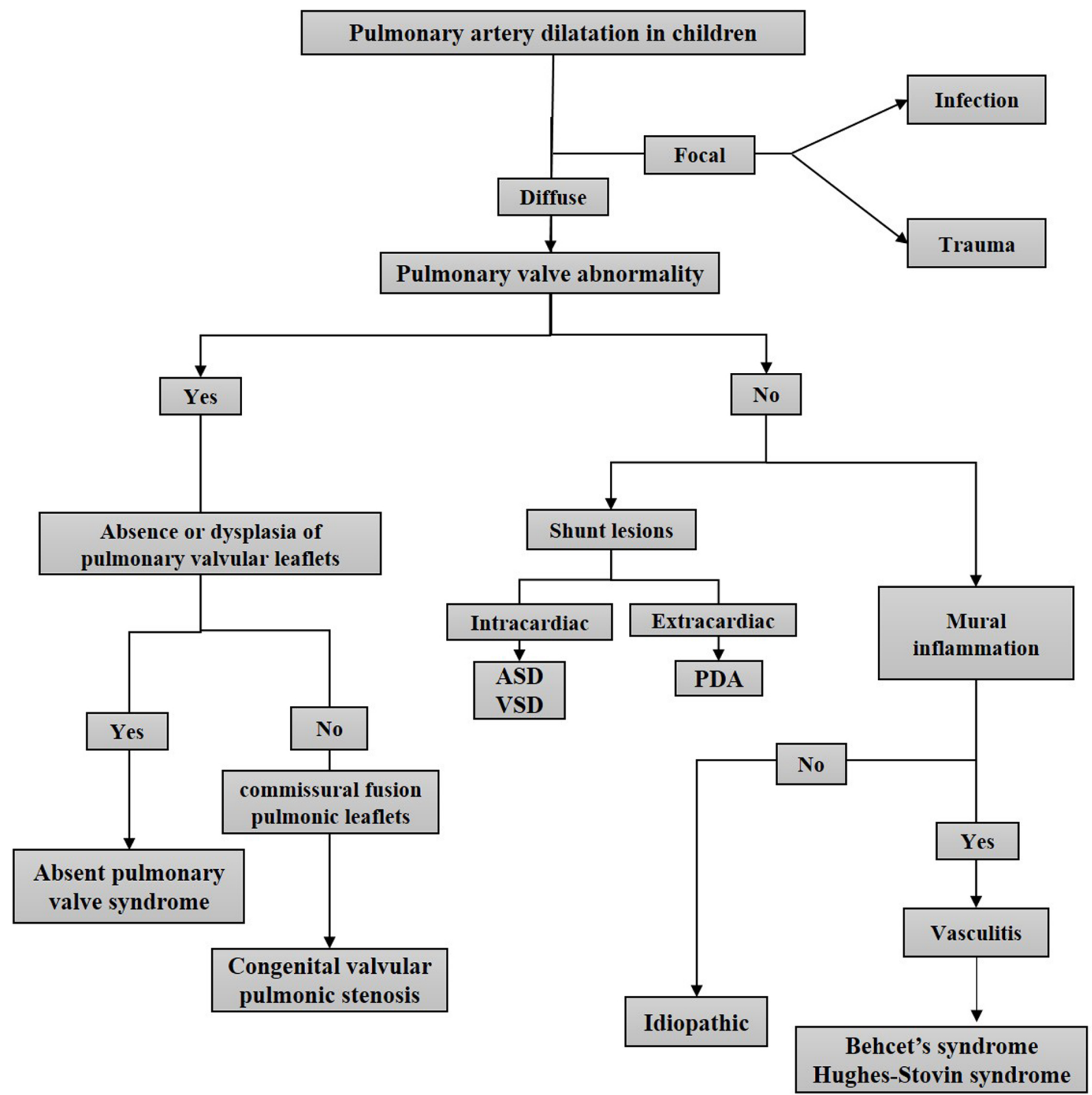

Fig. 1 Flowchart showing the algorithmic approach to the etiological diagnosis of pulmonary artery dilatation on MDCT angiography in the pediatric population. ASD, atrial septal defect; MDCT, multidetector computed tomography; PDA, patent ductus arteriosus; VSD, ventricular septal defect.

\section{Embryology and Anatomy}

The development of the vascular precursors of the pulmonary circulation begins when the endodermal lung bud invaginates into the precursor cardiac mesoderm which on subsequent specialization results in the anatomical and physiological relationship between the heart and the lungs via the specialized pulmonary circulation. The development of the pulmonary arteries begins with the formation truncus arteriosus and the sixth pharyngeal arch. The truncus arteriosus forms during the development of the heart as a successor to the conus arteriosus, which undergoes a spiral split via the conotruncal septum to form main pulmonary trunk and the ascending aorta. Right and the left pulmonary arteries develop from the ventral sixth arches. Dorsal portion of the right sixth arch involutes, however, dorsal left sixth arch forms the ductus arteriosus in intrauterine life. ${ }^{1}$
The pulmonary trunk arises from the outflow tract of right ventricle bifurcating into right and left pulmonary arteries with the root of the main pulmonary artery (MPA) guarded by the tricuspid pulmonic valve. Branching pattern of bilateral pulmonary arteries is dichotomous, forming up to 17 divisions from the level of hilar branches. In terms of relationship with the bronchi in the mediastinum, the right pulmonary artery (RPA) is located anteriorly and the left pulmonary artery (LPA) is positioned superiorly to the respective right and left main bronchi. At the hilum, the RPA bifurcates into the truncus anterior and the interlobar arteries. The truncus anterior supplies the right upper lobe, whereas the interlobar artery supplies the right middle and right lower lobes. The LPA has a shorter course before branching and usually gives apicoposterior branch, a separate branch to lingula and then terminate in branches to basal segments.,3 Histologically, there are three types of pulmonary arterial 


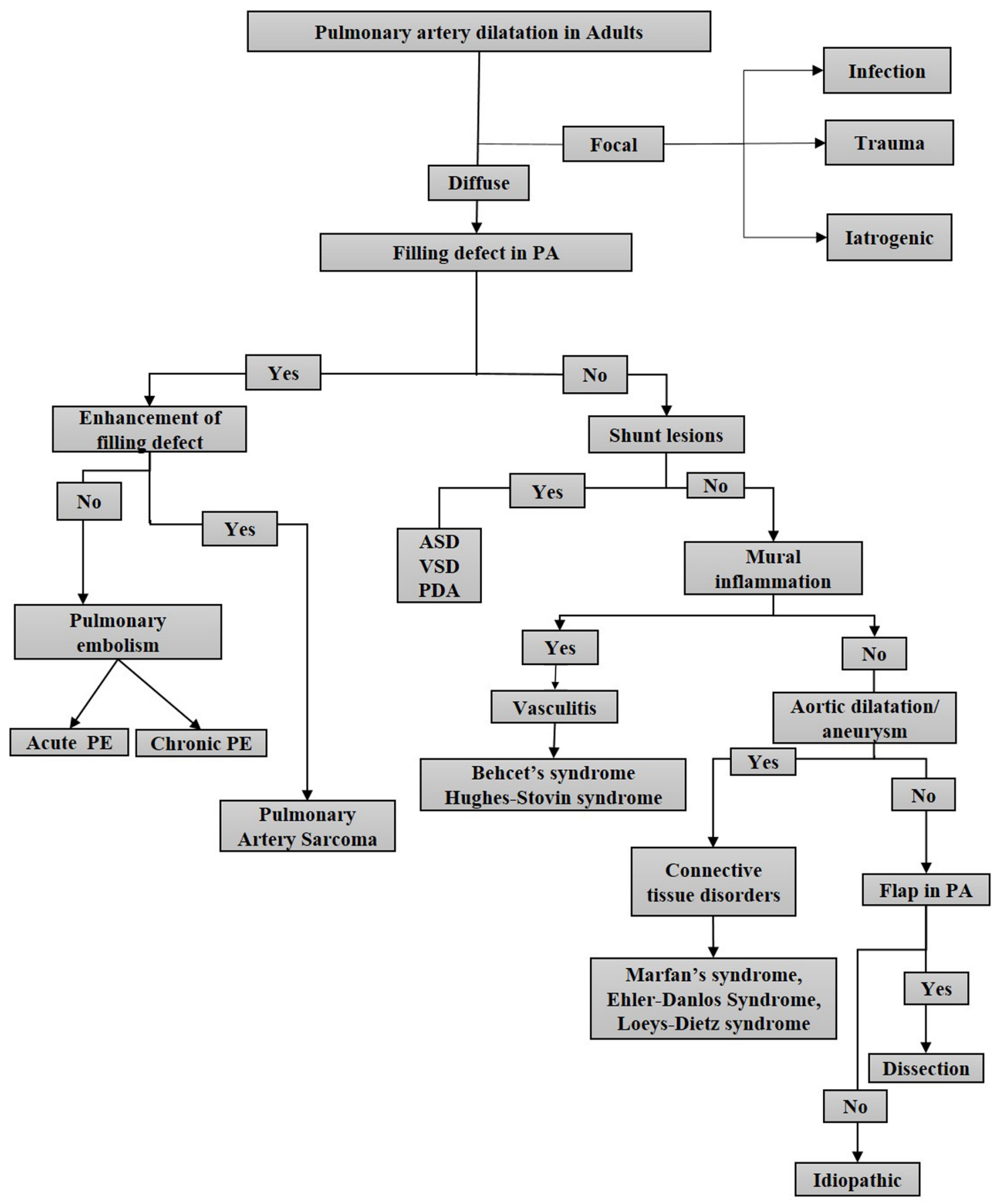

Fig. 2 Flowchart showing the algorithmic approach to the etiological diagnosis of pulmonary artery dilatation on MDCT angiography in the adult population. ASD, atrial septal defect; MDCT, multidetector computed tomography; PA, pulmonary artery; PDA, patent ductus arteriosus; $\mathrm{PE}$, pulmonary embolism; VSD, ventricular septal defect.

branches including the elastic, muscular, and transitional types. The large elastic arteries $(0.5$ to $>1 \mathrm{~mm}$ in diameter) accompany adjacent bronchi up to the subsegmental level. Muscular arteries are smaller and are located distally accompanying the smaller subsegmental airways up to the level of terminal bronchioles. They are characterized by the presence of media of smooth muscle fibers with distinct internal and external elastic laminae.,3 Transitional arteries are constituted by the pulmonary arterioles (usually smaller than $0.15 \mathrm{~mm}$ ) which accompany the respiratory bronchioles and the alveolar ducts and are distinguished by the absence of a distinct external elastic lamina.,3

\section{Multidetector CT Protocol for Pulmonary Assessment}

An 18-gauge cannula is preferably placed in the antecubital vein which is connected via the Y-tube to the pressure injector. Approximately 60 to $75 \mathrm{~mL}$ of nonionic low osmolar contrast medium (depending upon patient body weight, renal 


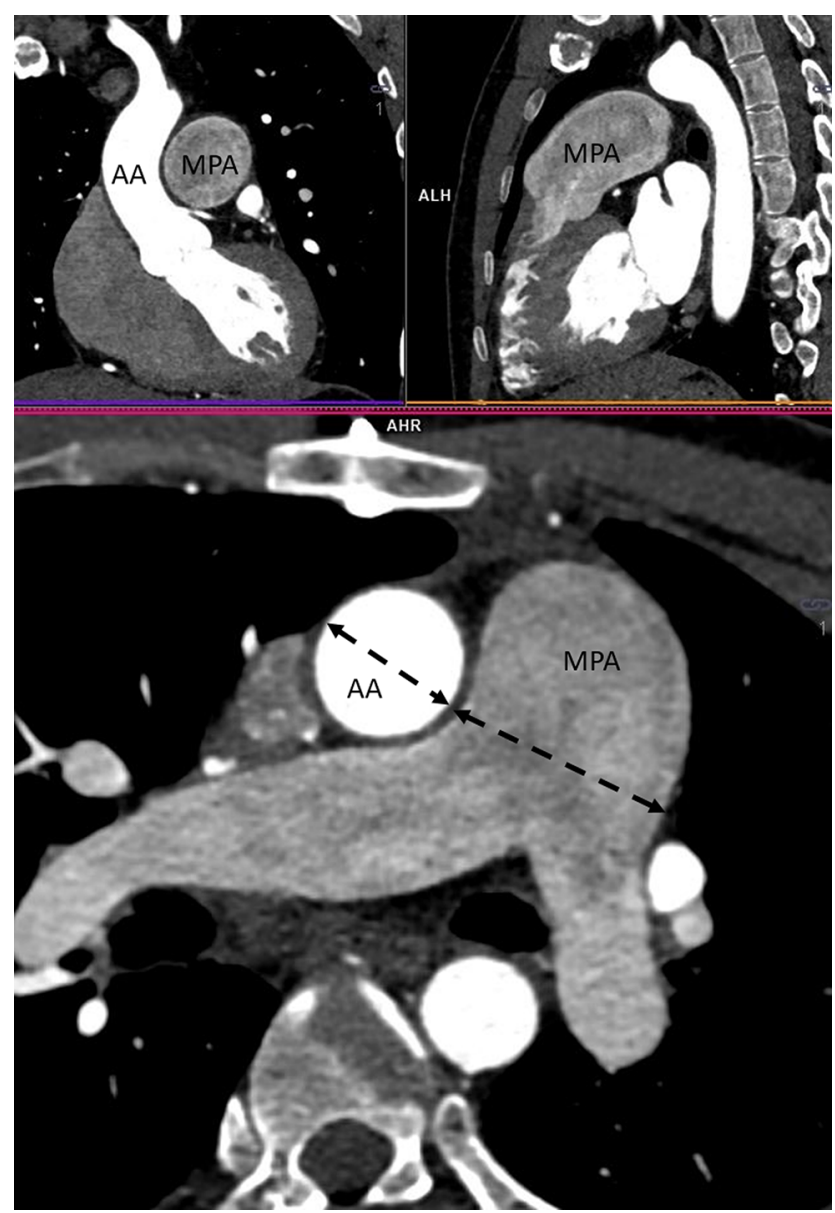

Fig. 3 Technique of measurement of main pulmonary artery (MPA). MPA measured $35.3 \mathrm{~mm}$ while the ascending aorta (AA) measured $20 \mathrm{~mm}$.

functions and clinical context) is injected at the predetermined flow rate (usually $4 \mathrm{~mL} / \mathrm{s}$ ) followed by approximately $30 \mathrm{~mL}$ of saline chase. From the initial tomogram, a low dose premonitoring image is acquired with region of interest placed in the MPA. Bolus tracking method is used to initiate the scan when the threshold of 80 Hounsfield units is detected in the MPA followed by which the scanning table moves to the caudal starting position and the patient is instructed to hold their breath for 2 to 6 seconds depending upon the scanner used. To reduce the Misregistration artifacts, the scanning protocol is set to be acquired in caudocranial direction as the excursion of the upper lobes is relatively less compared with the lower lobe if there is inadequate breath-hold during the acquisition. The reconstruction algorithms are applied to generate images with specific window width (WW) and window levels (WLs) at different gray scales for interpretation of lung (WW: $1500 \mathrm{HU}, \mathrm{WL}:-600 \mathrm{HU}$ ), mediastinum (WW: $350 \mathrm{HU}$; WL: $40 \mathrm{HU}$ ), and a specified preset to assess the extent of pulmonary embolism (WW: $700 \mathrm{HU}$; WL: $100 \mathrm{HU}$ ) with optimal slice thickness of 1 to $1.5 \mathrm{~mm} .^{5}$

\section{Technique of Measurement of Pulmonary Arteries on CT Pulmonary Angiography along with Reference Measurements}

The pulmonary arteries are assessed in the reconstructed slice thickness of 1 to $1.5 \mathrm{~mm}$ in the pulmonary embolism and mediastinal windows. The MPA is measured perpendicular to its long axis at its bifurcation in the true axial plane across its maximum dimensions (-Fig. 3). In healthy adults, the upper limits of diameters of the MPA, LPA, and RPA are $29.5 \mathrm{~mm}$, $22.1 \mathrm{~mm}$, and $19.8 \mathrm{~mm}$, respectively ${ }^{6-8}$ Moreover, sex-specific upper limit of the diameter of MPA (26.9 mm in women; $28.9 \mathrm{~mm}$ in men) has also been described. ${ }^{8}$ Apart from the absolute diameters of the MPA, the ratio of the diameter of MPA to the ascending aorta at the same corresponding level, up to 0.9 during the same phase of the cardiac cycle is considered the norm. ${ }^{8}$ However in the pediatric population, a slightly higher ratio of 1.085 may be considered normal. ${ }^{9}$ In addition, normal cut-off values for the pulmonary artery diameter and ratio of MPA to ascending aorta (MPA:AAo) can also be determined by the height of child, derived using following formulas, i.e., MPA $=1.05635 \times\left[\right.$ height $\left.{ }^{0.59132}\right]$, and MPA: AAo $=-0.002134 \times$ height $+1.343391 .^{10}$

Potential sources of measurement errors occur due to partial volume averaging in thick slice of $>3 \mathrm{~mm}$, poor window settings, and inadequate contrast opacification of the pulmonary arteries either due to early or delayed triggered acquisition leading to low contrast detail between the wall of the pulmonary artery and adjacent mediastinal tissues, inaccurate method of measurement in the oblique long axis proximal to the MPA bifurcation, measurement of the diameter in diastolic phase of the cardiac cycle, and inclusion of the wall of the arteries to consider for the upper limit calculation. All errors need to be avoided so as to provide a definite and objective assessment of the pulmonary artery dimensions.

\section{Dilative Lesions of the Pulmonary Arteries}

There are numerous etiologies for dilative lesions of the pulmonary arteries which are enumerated in - Table 1:

\section{Pulmonary Arterial Hypertension (PAH)}

$\mathrm{PAH}$ is characterized by elevated (greater than $25 \mathrm{~mm} \mathrm{Hg}$ ) mean pulmonary artery pressure. ${ }^{11}$ In 2013 , based on the etiological factors, WHO (World Health Organization) has classified PAH into five distinct groups. ${ }^{12}$ Group 1 constitutes pathology at precapillary and post-capillary pulmonary vessels with largely unknown underlying cause and may also include other disease entities such as pulmonary capillary hemangiomatosis and pulmonary veno-occlusive disease. Group 2 includes valvular and obstructive lesions of the left heart and is the most common type. Group 3 comprises of primary lung parenchymal pathologies including emphysema, pulmonary fibrosis which are associated with pulmonary 
vasoconstriction. Group 4 is characterized by chronic thromboembolic pulmonary hypertension. ${ }^{13}$ Group 5 comprises of the disease entities with unknown mechanisms not inclusive of either of the previous group entities.

On CT pulmonary angiogram, the dilated MPA with diameter $\geq 29 \mathrm{~mm}$ has shown $87 \%$ sensitivity, $89 \%$ specificity, and positive predictive value of $97 \%$ in diagnosing $\mathrm{PAH} .{ }^{14}$ Apart from the absolute diameters, MPA to ascending aorta diameter ratio (MPA: AAo) of $\geq 1.0$ is suggestive of PAH, particularly in patients aged $<50$ years in the absence of ectasia of the ascending aorta. ${ }^{15}$ Also in the presence of MPA dilatation, the ratio of diameter of segmental artery to accompanying

Table 1 Etiology of dilative lesions of the pulmonary arteries

\begin{tabular}{|l|l|}
\hline 1 & Pulmonary arterial hypertension \\
\hline 2 & $\begin{array}{l}\text { Due to turbulent blood flow } \\
\text { a. Congenital valvular pulmonary stenosis } \\
\text { b. Absent pulmonary valve syndrome }\end{array}$ \\
\hline 3 & $\begin{array}{l}\text { Due to increased blood flow } \\
\text { a. Intracardiac left to right shunts including VSD and } \\
\text { ASD and extracardiac left to right shunts including } \\
\text { PDA } \\
\text { b. Cyanotic lesions like truncus arteriosus }\end{array}$ \\
\hline 4 & Vasculitis: Behcet's and Hughes-Stovin syndrome \\
\hline 5 & $\begin{array}{l}\text { Connective tissue disorder: Marfan's syndrome, vascular } \\
\text { Ehler-Danlos syndrome, Loeys-Dietz syndrome }\end{array}$ \\
\hline 6 & $\begin{array}{l}\text { Infectious: } \\
\text { a. Mycotic } \\
\text { b. Tubercular } \\
\text { C. Fungal }\end{array}$ \\
\hline 7 & Trauma \\
\hline 8 & latrogenic \\
\hline 9 & Neoplasm: pulmonary sarcoma \\
\hline 10 & Pulmonary artery dissection \\
\hline 11 & Idiopathic \\
\hline
\end{tabular}

Abbreviations: ASD, atrial septal defect; PDA, patent ductus arteriosus; VSD, ventricular septal defect. bronchus $>1: 1$ in three or four lobes, has $100 \%$ specificity in diagnosing of PAH. ${ }^{12}$ In addition to pulmonary arterial dimensions, the presence of mural calcifications, tortuous pulmonary artery, and pruning of the peripheral pulmonary arterial branches has been seen in long standing cases of PAH. An additional marker evaluated on ECG-gated CT angiography is the reduced distensibility of the MPA (<16.5\%) which is an accurate marker of PAH with sensitivity and specificity of 86 and $96 \%$, respectively. ${ }^{16}$ Special attention should be paid to the adjacent structures including left main coronary artery and the tracheobronchial tree as they can be compressed by the dilated MPA, with higher risk when MPA diameter is $>4 \mathrm{~cm}$ and MPA:AAo ratio of $>1.21 .^{17}$

Pulmonary thromboembolism constitutes an important cause of pulmonary artery dilatation. Acute pulmonary thrombus is seen as a hypodense filling defect forming an acute angle with the wall of the artery ( - Fig. 4A,B). The presence of eccentric bland thrombus forming an obtuse angle with the wall of the artery, hypodense webs (-Fig. 4C), luminal stenosis or abrupt cut-off, post-stenotic dilatations, and outpouching are suggestive of chronic pulmonary thromboembolism. ${ }^{18}$ Chronic pulmonary arterial thrombus contracts the lumen in contradistinction to acute embolus which distends the lumen. ${ }^{11}$ Valuable indirect imaging signs of chronic thromboembolic pulmonary hypertension (CTEPH) to distinguish from other causes of PAH include mosaic attenuation of lung parenchyma due to alternating areas of hypoperfusion and hyperperfusion, tortuous pulmonary vessels, peripheral infarcts seen as wedge-shaped consolidation with apex truncation and a feeding vessel, hypertrophied systemic arterial collaterals including bronchial arteries (associated with up to $73 \%$ of the CTEPH cases vs. $14 \%$ in primary pulmonary hypertension), pleural and intercostal arteries and presence of pulmonary artery webs/bands with focal stenotic segments. ${ }^{19,20}$ The therapeutic options in CTEPH can be derived based on the location and extent of thrombus visualized on CT angiography. Pulmonary endarterectomy is beneficial if predominant thrombus is seen in the main, lobar, or proximal

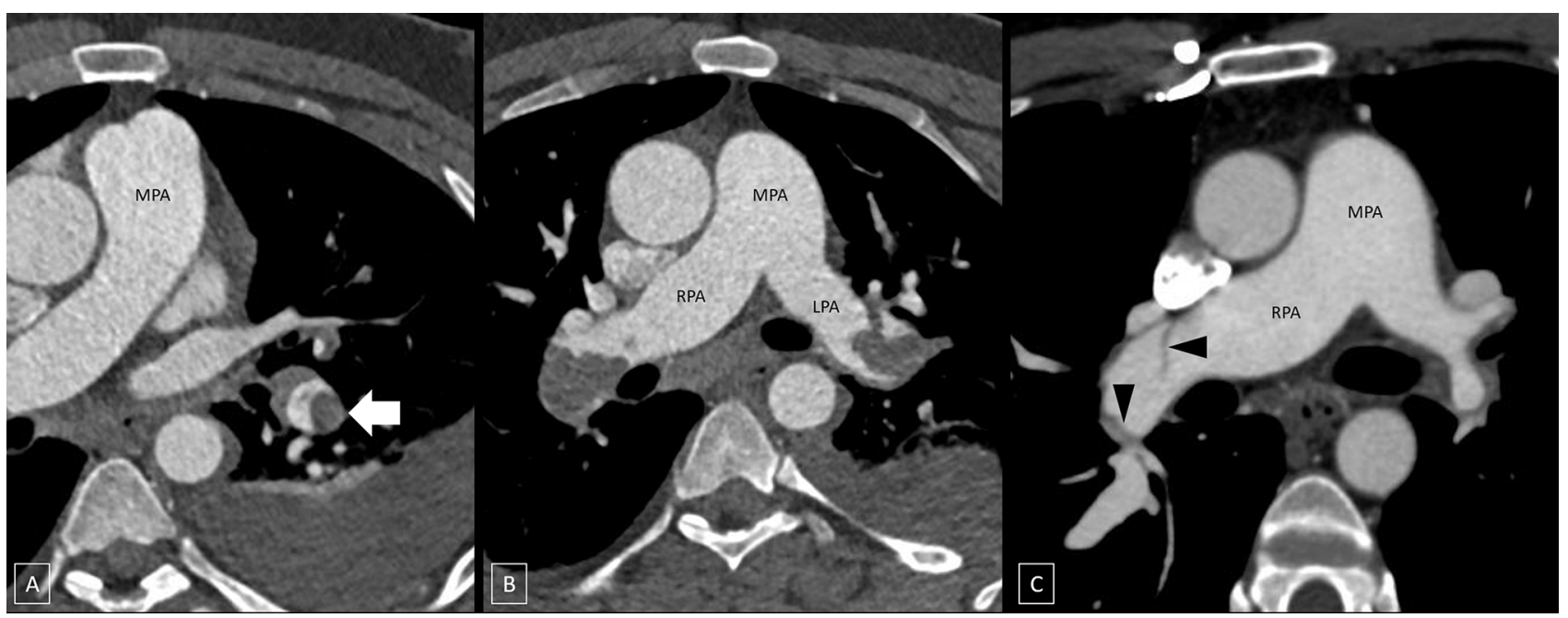

Fig. 4 (A) Acute embolus (white arrow) in the left descending pulmonary artery forming acute angle with the wall of the artery. (B) Acute thrombus in the right pulmonary artery (RPA) and left pulmonary artery (LPA) placed eccentrically along the arterial wall. (C) Hypodense web (black arrowhead) in the right descending pulmonary artery. MPA, main pulmonary artery. 
segmental arteries, whereas medical therapy is preferred in distal disease.

\section{Congenital Valvular Pulmonic Stenosis}

In general, congenital pulmonary stenosis in seen in up to $10 \%$ of the patients with congenital heart diseases of which the valvular type of pulmonary stenosis comprises nearly $90 \%$ of the cases apart from the subvalvular and supravalvular varieties.,21,22 The primary pathology is commissural fusion of the tricuspid pulmonic valve leaflets resulting in inadequate opening of the valve leaflets during the ventricular systolic phase. Clinical presentation is primarily determined by the gradient across the stenotic valve, varying from asymptomatic patients to the systemic venous congestion secondary to right heart failure. On retrospective-gated CT angiography, thickening of the pulmonary valve leaflets with restricted mobility is seen in systolic and diastolic phases of the cardiac cycle (- Fig. 5A). There is also significant post-stenotic dilatation of the MPA and the LPA due to the preferential leftward jet of the flow across the stenosed valve (-Fig. 5B). Moreover, doming of the pulmonary valve, leaflet calcification, and hypertrophy of the right ventricle may also be seen. ${ }^{2}$

\section{Absent Pulmonary Valve Syndrome}

The primary pathology is characterized by the absence or dysplasia of pulmonary valvular leaflets resulting in the dilatation of the main and the branch pulmonary arteries secondary to regurgitation physiology. In approximately $25 \%$ of the cases, the syndrome is seen associated with 22q11 chromosome microdeletion. ${ }^{23,24}$ On CT angiography thickening of the hypoplastic pulmonary valve leaflets is seen with dilated main and branch pulmonary arteries (-Fig. 6). Ventricular septal defect is the most common association. In cases with an intact ventricular septum, the pulmonary arteries are relatively small in size with patent ductus arteriosus and tricuspid atresia as their common associations. The regurgitation physiology and the presence of ventricular septal defect result in cardiomegaly secondary to raised end diastolic pressures in the right heart chambers. In addition to cardiomegaly, the presence of bronchomalacia

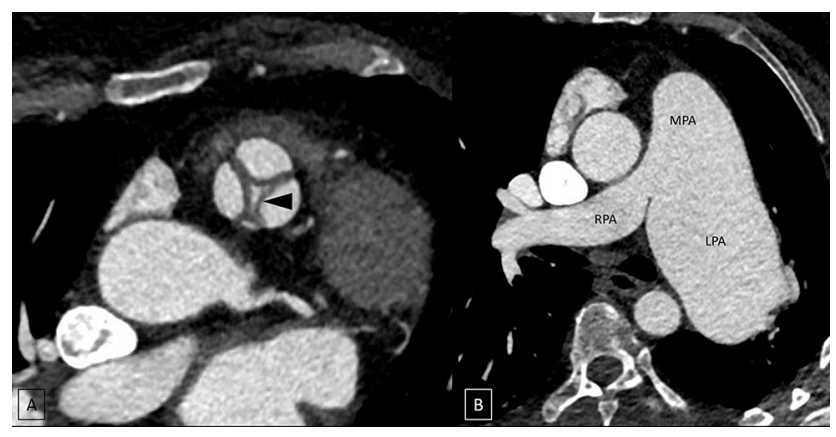

Fig. 5 (A) Axial section at the level of pulmonary valve and the aortic sinus showing thickening of the pulmonary valve leaflets (black arrowhead). (B) Axial section at the main pulmonary artery (MPA) bifurcation showing disproportionate dilatation of the MPA and left pulmonary artery (LPA). RPA, right pulmonary artery. is associated with poor prognosis in this subset of patients. In utero, secondary to compression of the esophagus and the trachea-bronchial tree by the dilated pulmonary arteries, there is obstruction to the physiological amniotic fluid circulation leading to polyhydramnios.

\section{Secondary to Underlying Intra- and Extracardiac Shunts}

Common causes of left to right shunts include atrial septal defect ( - Fig. 7A), ventricular septal defect ( - Fig. 7B,C), and patent ductus arteriosus (-Fig. 8A,B). Significant shunts result in volume and pressure overload of pulmonary artery resulting in its dilatation. Usually no sex predilection is observed, except in atrial septal defect where females are mostly affected. Cyanotic lesions like truncus arteriosus can also result in pulmonary artery dilatation (-Fig. 9). Elevated hemodynamic shear stress and increased flow due to the underlying defect lead to vascular remodeling including wall thickening, adventitial fibroblast proliferation increasing the wall stiffness, eventually increasing the pulmonary vascular resistance, leading to dilatation of central pulmonary arteries. ${ }^{25,26}$ Mural calcification can also result from the accelerated atherosclerotic changes secondary to long standing severe pulmonary hypertension. The dilated pulmonary arteries can cause extrinsic compression of the coronary arteries, and the adjacent bronchi leading to atelectasis. The ECG-gated CT angiography will reveal both the underlying cardiac shunts and features of pulmonary dilatation, which would guide in the treatment and prognosis of the patient.

\section{Vasculitis}

Behcet's syndrome and Hughes-Stovin syndrome are the most common vasculitic disorders associated with pulmonary artery dilatation. Both the disease entities are considered to be part of the spectrum of similar pathological expression, with Hughes-Stovin syndrome lacking classical clinical features of Behcet's syndrome which include oral ulcers, genital ulcers, and uveitis. In Behcet's syndrome, CT angiography reveals focal dilatation/aneurysms of bilateral pulmonary vasculature with right lower lobe arteries being most commonly involved with associated mural inflammation and thrombosis of the aneurysm sac (-Fig. 10). ${ }^{27}$ Although the immune-suppressive therapy may lead to regression of the dilatation, the patients presenting with life threatening hemoptysis often need embolization. CT angiography depicts the spectrum of the imaging findings including the pulmonary hemorrhage, infarction, pericardial, and pleural effusions in addition to pulmonary vascular involvement. Similar to Behcet's, Hughes-Stovin syndrome leads to pulmonary arterial dilatation, secondary to mural inflammation and weakening the arterial wall. ${ }^{28} \mathrm{CT}$ angiography shows enhancing pulmonary arterial wall (secondary to vasculitis), pulmonary thromboembolism, and dysplastic tortuous bronchial arteries. The ongoing vasculitis and accompanying thrombus form a nidus for the development of pulmonary aneurysms which may rupture in severe cases. 


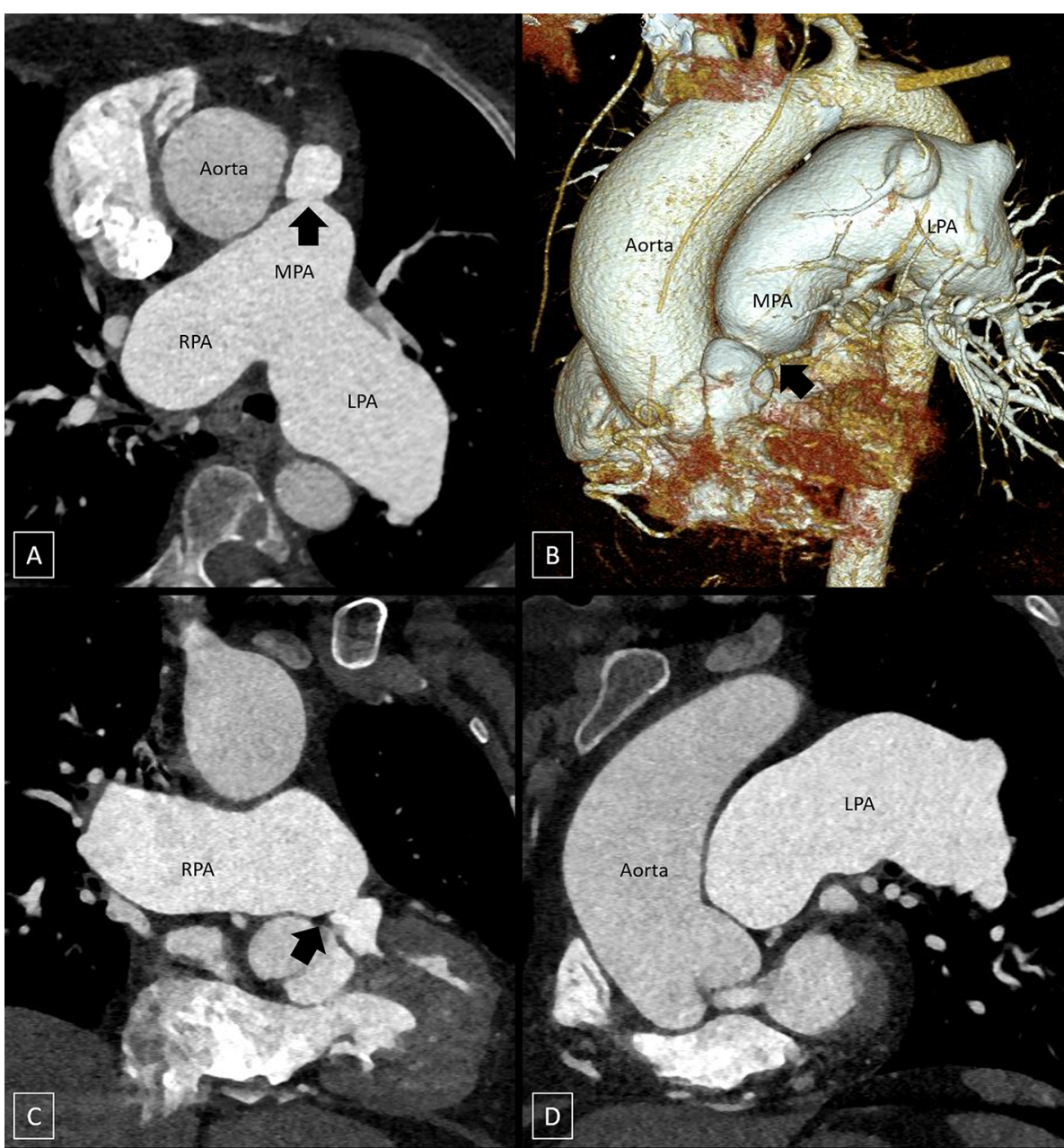

Fig. 6 Multiplanar reconstruction (MPR) images (A, C and D) and volume-rendered image (B) show constriction (black arrow) at the level of the annulus of the main pulmonary artery (MPA) with dilatation of the MPA, left pulmonary artery (LPA), and right pulmonary artery (RPA) with hypoplastic pulmonary valve leaflets.

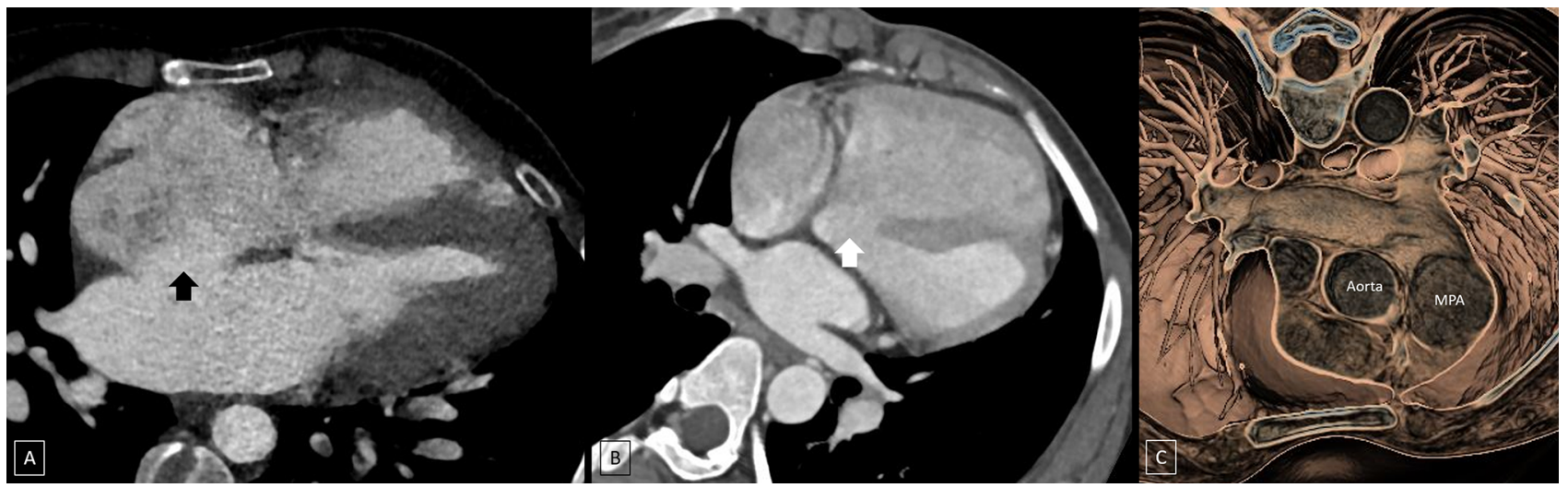

Fig. 7 Four chamber view of the heart (A) showing atrial septal defect (black arrow). Oblique axial image (B) and virtual dissection image (C) of a different patient shows a ventricular septal defect (white arrow) and dilated main pulmonary artery (MPA), respectively.

\section{Connective Tissue Disorders}

Congenital deficiency of the intercellular matrix in the wall of the arteries seen in the connective tissue disorders such as Marfan's syndrome, Ehler-Danlos Syndrome, LoeysDietz syndrome, and cystic medial necrosis typically causes the aorta ectasia and dilatation. ${ }^{29,30}$ Marfan's syndrome is autosomal dominant disease characterized by abnormal microfibrils due to Fibrillin-1 gene mutation. The Ghnet 2 criteria considers the various musculoskeletal manifestation and aortic dilatation as the typical clinical features of the disease. However, dilatation of the MPA as well as the root of the pulmonary trunk is also a relatively common finding in Marfan's syndrome (seen in up to $74-76 \%$ of the cases), and is usually not related to the high pressures and is clinically asymptomatic ( - Fig. 11) ${ }^{29}$ 


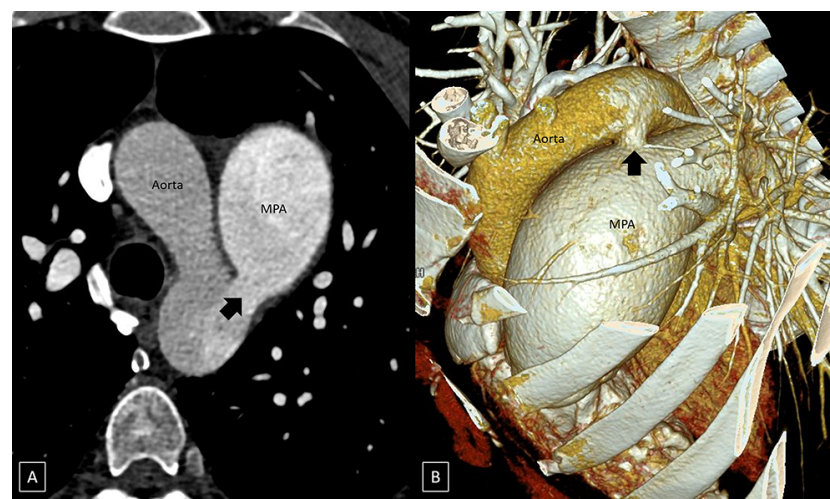

Fig. 8 Multiplanar reconstruction image (A) and volume-rendered image (B) showing patent ductus arteriosus (black arrow) with dilated main pulmonary artery (MPA).

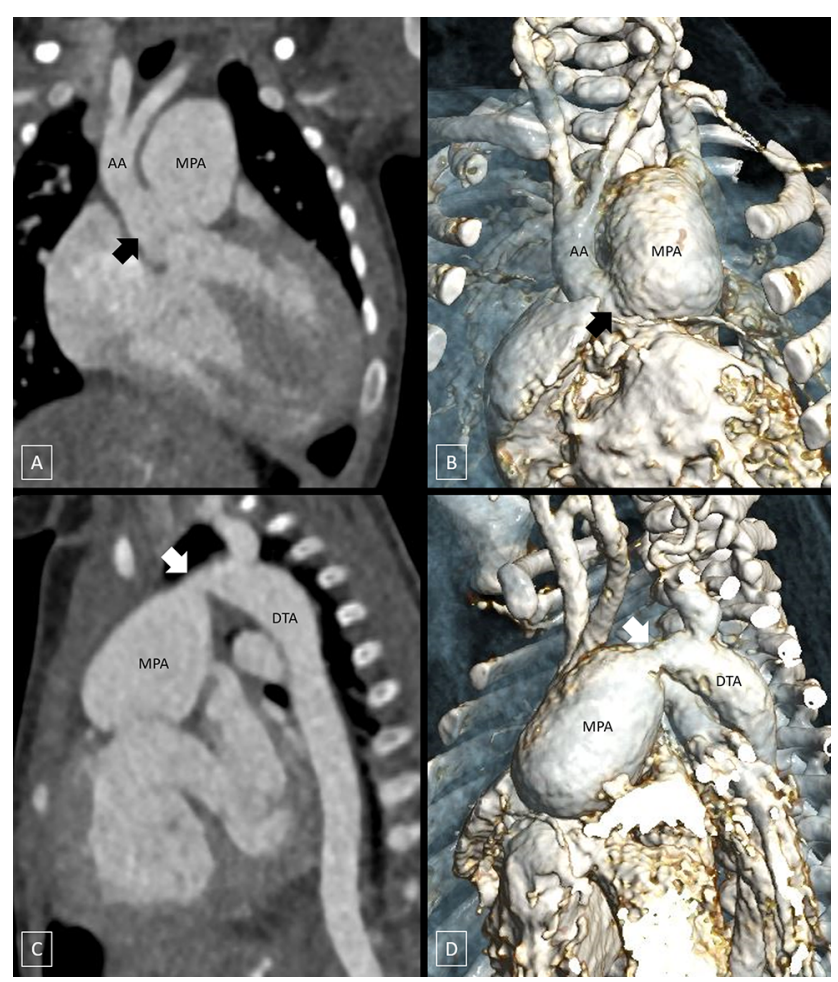

Fig. 9 Multiplanar reconstruction image (A) and volume-rendered image (B) showing type I truncus arteriosus with common truncus channel (black arrow). Multiplanar reconstruction image (C) and volume rendered image (D) show Type B interrupted aortic arch with patent ductus arteriosus (white arrow) reforming the descending thoracic aorta (DTA). AA, ascending aorta; MPA, main pulmonary artery.

Loeys-Dietz syndrome is autosomal dominant condition due to mutation in TGRBR2 gene leading to the loss of elastin content in the tunica media of the arterial walls. Although the exact prevalence is unknown, pulmonary artery dilatation is usually seen in Loeys-Dietz syndrome in patients with additional congenital cardiac shunts. Vascular Ehler-Danlos syndrome is a rare genetic disease characterized by procollagen III deficiency secondary to COLA3A1 gene mutation; pulmonary artery aneurysm is seen rarely due to the deficiency of the vessel wall.

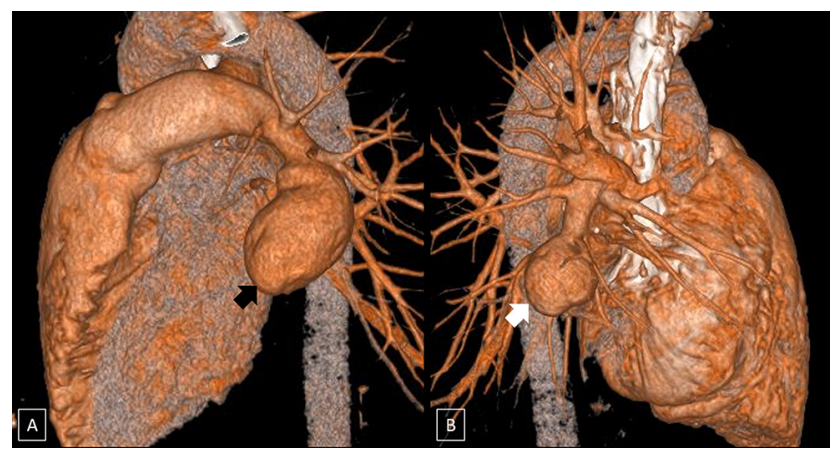

Fig. 10 Volume-rendered images (A and $\mathbf{B}$ ) showing pseudoaneurysms of the left descending pulmonary artery (black arrow) and the right descending pulmonary artery (white arrow), respectively.

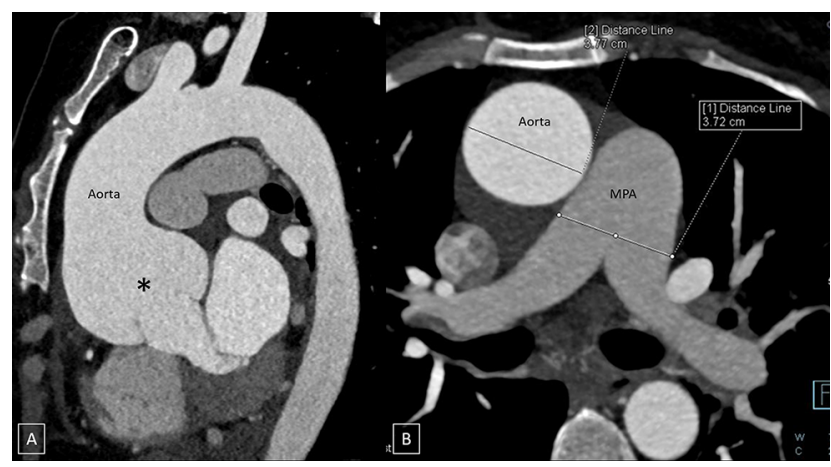

Fig. 11 (A) Sagittal oblique images show dilated aortic sinus ( ${ }^{*}$ ) and ascending aorta. (B) Oblique axial section showing dilated main pulmonary artery (MPA) and dilated ascending aorta.

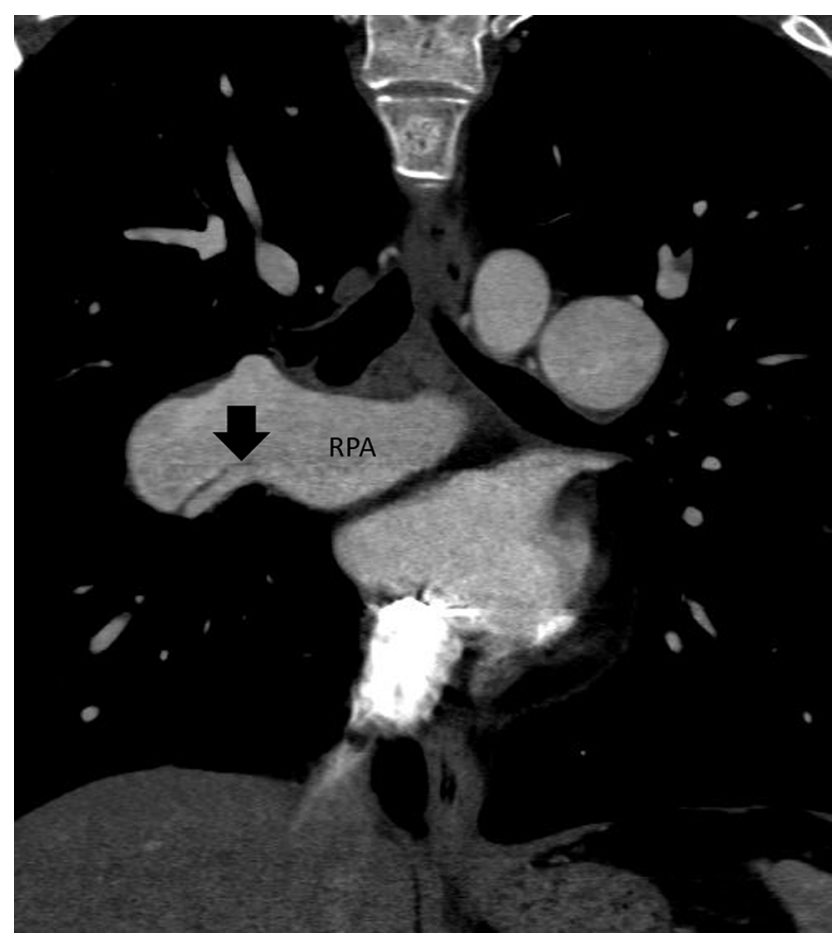

Fig. 12 Hypodense dissection flap (black arrow) in the right lower descending pulmonary artery with dilated right pulmonary artery (RPA). 


\section{Infectious Etiology}

Virulent infections produce necrosis of the arterial wall secondary to the occlusion of the vasa vasorum by the septic emboli leading to the formation of pseudoaneurysms of the pulmonary artery. Most common organisms include Staphylococcus, Streptococcus, Mycobacteria, Aspergillus, and Candida Albicans. ${ }^{31-34}$ Pseudoaneurysms secondary to infective etiology are usually associated with hemoptysis and pulmonary parenchymal hemorrhage leading to abrupt clinical deterioration. The diagnosis of mycotic aneurysms is usually made on the background of spectrum of CT imaging findings suggestive of infective pathology such as pulmonary parenchymal consolidation, ground glass opacities, pneumonic effusion, and enlarged enhancing mediastinal and hilar lymph nodes. The mycotic pulmonary artery aneurysms are well visualized in the subacute and chronic stages of infection as areas of fusiform or saccular dilatations with the enhancement similar to adjacent artery and often the feeding vessel can also be identified to differentiate it from bronchial artery aneurysms. ${ }^{32,33}$ Rasmussen aneurysms are seen in up to $5 \%$ cases of the reactivation of pulmonary tuberculosis adjacent to or within the chronic tubercular cavitary lesions, and predominantly involve the branches of the right upper lobe pulmonary artery ${ }^{34}$ Rarely pulmonary artery pseudoaneurysm has also been described in hyper-IgE syndrome which by itself is a rare multisystem disorder. ${ }^{35} \mathrm{CT}$ angiography remains the imaging modality of choice to diagnose mycotic and Rasmussen aneurysms and also provides a guide for excellent localization of the aneurysm and the involved vessels for appropriate endovascular or surgical management.

\section{Neoplastic-Pulmonary Artery Sarcoma}

Pulmonary artery sarcoma is fatal neoplasm with rare incidence of 0.001 to $0.03 \%$. The lesion is seen to arise from intimal mesenchymal cells and is often misdiagnosed as thrombus. ${ }^{36}$ MDCT findings suggestive of diagnosis include a hypodense persistent filling defect despite adequate anticoagulation, completely filling the lumen of main or proximal pulmonary arteries with associated expansion of the affect arteries and extraluminal extension. ${ }^{36,37}$ Moreover, a slower onset with associated systemic symptoms and no history of venous thromboembolism or positive hypercoagulability in patients who are nonresponsive to anticoagulation helps in differentiation from pulmonary thromboembolism. Since FDG-PET has superior sensitivity in detecting pulmonary sarcoma due to high FDG uptake, MDCT is usually complemented with FDG-PET in complete noninvasive imaging evaluation of pulmonary sarcomas. ${ }^{38}$

\section{Trauma}

Pulmonary artery pseudoaneurysms are rare in penetrating chest trauma and occur due to injury to layers of the arterial wall, contained by the extravascular tissue and clot with absence of true endothelial lining. ${ }^{39}$ It is frequently associated with hemothorax, pulmonary hemorrhage, chest wall injuries, and rib fractures. Multiple treatment options include transcatheter embolization, thrombin injection, emergency surgical ligation, and lobectomy. CT angiography depicts the pseudoaneurysm as circumscribed enhancing mass, isodense to the adjacent pulmonary artery. ${ }^{38} \mathrm{CT}$ angiography has also been used in follow-up of conservative management of small PA pseudoaneurysm in clinically stable, asymptomatic patients where spontaneous resolution has been reported in literature, although very rare. ${ }^{40,41}$

\section{latrogenic}

Iatrogenic pulmonary artery pseudoaneurysm is a rare complication seen in 0.001 to $0.47 \%$ of the patients who undergo catheterization and is most commonly caused by a malpositioned Swan-Ganz catheter causing erosion and weakening of the arterial wall. ${ }^{27,39}$ Other possible mechanisms include retraction of inflated balloon and balloon inflations at too high pressures. The clinical presentation is usually seen shortly after the catheter insertion with the immediate onset of cough, hemoptysis, and hypoxemia, although pseudoaneurysm has been reported up to 7 months after the interventional procedure. ${ }^{42}$ It is seen commonly on the right side, involving the right middle lobe and right lower lobe branches, which may be related to common location of Swan-Ganz catheter. ${ }^{43,44}$ CT pulmonary angiography usually reveals a saccular aneurysm isodense to the adjacent involved vessel with an occasional partial thrombus in the aneurysmal sac. Endovascular embolization is a treatment option in catheter-induced pseudoaneurysms; in this regard CT angiography guides in the therapeutic planning of embolization by delineating the feeding vessel size and the aneurysm sac dimension. ${ }^{42-46}$ Other causes of iatrogenic pulmonary artery pseudoaneurysms include chest tube insertion, conventional pulmonary angiography, and thoracic surgery; hence the clinical history and presenting complaints are of utmost importance when considering this disease entity.

\section{Pulmonary Artery Dissection}

Dissection of the pulmonary artery presents as one of the rare and dreaded complication of chronic pulmonary arterial hypertension. Trauma, infective endocarditis involving the right heart chambers, amyloidosis, chronic pulmonary artery inflammation, and severe atherosclerosis are other proposed causes of pulmonary artery dissection. ${ }^{47,48}$ This clinical condition is to be considered in PAH patients who present with chest pain, central cyanosis, and cardiogenic shock. Dissection is usually seen at the point of maximal arterial dilatation and is usually associated with medial degeneration of the arterial wall. It has an increased propensity to rupture rather than developing a reentry tear, unlike the aortic dissection. ${ }^{49}$ Though echocardiography is the first line of investigation, CT angiography has the ability to define the complete extent of the dissection flap, false lumen thrombosis, and provide a clue to underlying etiology of the dissection (-Fig. 12). CT angiography detects hemopericardium secondary to PA dissection extending into the pericardium..$^{50} \mathrm{CT}$ angiography can also confidently exclude pulmonary arterial thromboembolism, which can also have similar clinical presentation. $^{51}$ 


\section{Idiopathic Dilatation of the Pulmonary Trunk}

It is a diagnosis of exclusion when all the cardiac and pulmonary causes for the pulmonary arterial dilatation have been ruled out. It is a rare congenital anomaly with an incidence of up to $0.6 \% .^{52}$ Clinical symptoms are highly variable with patient being asymptomatic to the development of exertional dyspnea. Although the initial postulated mechanism for the development of idiopathic dilatation was unequal division of the truncus arteriosus communis, currently the most accepted theory is the presence of congenital weakness in the wall of the pulmonary artery. ${ }^{53-55}$ MDCT angiography defines the location, extent of dilatation of the pulmonary artery, and also rules out imaging features of other etiologies that would lead to pulmonary artery dilatation as described previously. Even though there are no established guidelines, surgical repair is advised if the aneurysm is $>6 \mathrm{~cm}$ in size or having symptomatic disease or the aneurysm is at risk of rupture, dissection, or thromboembolism..$^{55-57}$

Table 2 Summary of imaging findings in various etiologies causing pulmonary artery dilatation

\begin{tabular}{|c|c|}
\hline Etiology & Summary of cardiovascular imaging findings \\
\hline PAH & $\begin{array}{l}\text { Dilated MPA with diameter } \geq 29 \mathrm{~mm} \\
\text { MPA to AA diameter ratio of } \geq 1.0^{\mathrm{a}} \\
\text { In presence of MPA dilatation, ratio of diameter of segmental artery to accompanying bronchus }>1: 1 \text { in } \geq 3 \text { lung lobes } \\
\text { Mural calcifications, tortuous PA branches, and pruning of the peripheral PA branches }\end{array}$ \\
\hline PTE & $\begin{array}{l}\text { Acute PTE: } \\
\text { Hypodense filling defect forming acute angle with PA wall } \\
\text { Chronic PTE: } \\
\text { Eccentric thrombus forming obtuse angle with PA wall, hypodense webs, luminal stenosis or abrupt cut- } \\
\text { off, post-stenotic dilatations } \\
\text { Hypertrophied systemic arterial collaterals }\end{array}$ \\
\hline $\begin{array}{l}\text { Congenital valvu- } \\
\text { lar PS }\end{array}$ & $\begin{array}{l}\text { PV leaflet thickening with restricted mobility in systole and diastole } \\
\text { Doming of PV } \\
\text { PV leaflet calcification } \\
\text { Post-stenotic dilatation of MPA and LPA } \\
\text { RV hypertrophy }\end{array}$ \\
\hline $\begin{array}{l}\text { Absent PV } \\
\text { syndrome }\end{array}$ & $\begin{array}{l}\text { Absent/rudimentary hypoplastic PV leaflets } \\
\text { With VSD: dilated main and branch PAs } \\
\text { With intact ventricular septum: PAs are relatively small in size with PDA } \\
\text { RV dilatation }\end{array}$ \\
\hline Cardiac shunts & ASD, VSD, PDA, truncus arteriosus \\
\hline Vasculitis & $\begin{array}{l}\text { Focal dilatation/aneurysms of bilateral PAs predominantly in right lower lobe } \\
\text { Enhancing PA wall } \\
\text { Pulmonary thrombo-embolism } \\
\text { Dysplastic tortuous bronchial arteries }\end{array}$ \\
\hline $\begin{array}{l}\text { Connective tissue } \\
\text { disorders }\end{array}$ & $\begin{array}{l}\text { Marfan's syndrome: } \\
\text { Annulo-aortic ectasia giving “tulip bulb” appearance } \\
\text { Dilatation of the MPA as well as the root of pulmonary trunk } \\
\text { Loeys-Dietz syndrome: } \\
\text { Arterial tortuosity, arterial aneurysms, PA dilatation } \\
\text { Vascular Ehler-Danlos syndrome: } \\
\text { PA aneurysm, aortic dilatation }\end{array}$ \\
\hline Infection & $\begin{array}{l}\text { Mycotic aneurysms: } \\
\text { Fusiform or saccular PA dilatations } \\
\text { Rasmussen aneurysm: } \\
\text { Predominantly involves branches of the right upper lobe PA adjacent to or within chronic tubercular } \\
\text { cavity }\end{array}$ \\
\hline PA Sarcoma & $\begin{array}{l}\text { Hypodense persistent filling defect despite adequate anticoagulation, completely filling the lumen of main or proxi- } \\
\text { mal PAs with associated expansion and extraluminal extension. }\end{array}$ \\
\hline Trauma & PA pseudoaneurysm \\
\hline latrogenic & $\begin{array}{l}\text { Predominantly involves middle lobe and lower lobe branches of RPA } \\
\text { Saccular aneurysm with occasional partial thrombus in the sac }\end{array}$ \\
\hline PA dissection & $\begin{array}{l}\text { Dissection flap at the point of maximal PA dilatation } \\
\text { Complete or partial false lumen thrombosis }\end{array}$ \\
\hline $\begin{array}{l}\text { Idiopathic dilata- } \\
\text { tion of the pulmo- } \\
\text { nary trunk }\end{array}$ & Diagnosis of exclusion \\
\hline
\end{tabular}

Abbreviations: AA, ascending aorta; ASD, atrial septal defect; LPA, left pulmonary artery; MPA, main pulmonary artery; PA, pulmonary artery; PAH, pulmonary arterial hypertension; PDA, patent ductus arteriosus; PS, pulmonic stenosis; PTE, pulmonary thromboembolism; PV, pulmonic valve; RPA, right pulmonary artery; RV, right ventricle; VSD, ventricular septal defect.

aParticularly in patients aged $<50$ years in the absence of ectasia of the ascending aorta.

bIn relation to location of tip of Swan-Ganz catheter. 


\section{Conclusion}

Pulmonary artery dilatation is often detected either incidentally or in patients with respiratory symptoms and is often a nonspecific manifestation with a multitude of possible etiologies. While a chest radiograph is often the initial imaging modality which detects pulmonary artery dilatation, cross sectional imaging evaluation, usually in the form of CT allows optimal assessment of pulmonary arteries per se without superimposition of hilar and mediastinal structures. With the advent of multidetector CT, noninvasive CT pulmonary angiography has become the first line imaging modality for the evaluation of pulmonary arteries and their branches. In an appropriate clinical setting, CT pulmonary angiography plays an important role in early and accurate diagnosis of these pathologies and in delineating the complete extent of pulmonary artery lesions (- Table 2). Moreover, it allows detection of associated lung parenchymal changes and other associated conditions for optimal management, prognostication, and follow-up of these patients.

\section{Authors' Contributions}

All authors contributed to the conception or design, literature search, drafting, critical revision, and final approval of the manuscript.

\section{Funding Information \\ None.}

\section{Conflict of Interest}

None declared.

\section{Acknowledgments}

None.

\section{References}

1 Escalon JG, Browne LP, Bang TJ, Restrepo CS, Ocazionez D, Vargas D. Congenital anomalies of the pulmonary arteries: an imaging overview. Br J Radiol 2019;92(1093):20180185

2 Carter BW, Lichtenberger JP III, Wu CC. Congenital abnormalities of the pulmonary arteries in adults. AJR Am J Roentgenol 2014;202(4):W308-13

3 McLoud TC, Boiselle PM, Thoracic radiology: imaging methods, radiographic signs, and diagnosis of chest disease. In: McLoud TC, Boiselle PM, eds. Thoracic Radiology: The Requisites. 2nd ed. Philadelphia, PA: Elsevier; 20108

4 Frazier AA, Galvin JR, Franks TJ, Rosado-De-Christenson ML. From the archives of the AFIP: pulmonary vasculature: hypertension and infarction. Radiographics 2000;20(2):491-524, quiz 530-531, 532

5 Wittram C. How I do it: CT pulmonary angiography. AJR Am J Roentgenol 2007;188(5):1255-1261

6 Bozlar U, Ors F, Deniz O, et al. Pulmonary artery diameters measured by multidetector-row computed tomography in healthy adults. Acta Radiol 2007;48(10):1086-1091

7 Aluja Jaramillo F, Gutierrez FR, Díaz Telli FG, Yevenes Aravena S, Javidan-Nejad C, Bhalla S. Approach to pulmonary hypertension: from $\mathrm{CT}$ to clinical diagnosis. Radiographics 2018;38(2):357-373

8 Truong QA, Massaro JM, Rogers IS, et al. Reference values for normal pulmonary artery dimensions by noncontrast cardiac computed tomography: the Framingham Heart Study. Circ Cardiovasc Imaging 2012;5(1):147-154

9 Compton GL, Florence J, MacDonald C, Yoo SJ, Humpl T, Manson D. Main pulmonary artery-to-ascending aorta diameter ratio in healthy children on MDCT. AJR Am J Roentgenol 2015;205(6):1322-1325

10 Chen SJ, Huang JH, Lee WJ, Lin MT, Chen YS, Wang JK. Diagnosis of pulmonary arterial hypertension in children by using cardiac computed tomography. Korean J Radiol 2019;20(6):976-984

11 McLaughlin VV, Archer SL, Badesch DB, et al. American College of Cardiology Foundation Task Force on Expert Consensus DocumentsAmerican Heart AssociationAmerican College of Chest PhysiciansAmerican Thoracic Society, IncPulmonary Hypertension Association. ACCF/AHA 2009 expert consensus document on pulmonary hypertension a report of the American College of Cardiology Foundation Task Force on Expert Consensus Documents and the American Heart Association developed in collaboration with the American College of Chest Physicians; American Thoracic Society, Inc.; and the Pulmonary Hypertension Association. J Am Coll Cardiol 2009;53(17):1573-1619

12 Simonneau G, Gatzoulis MA, Adatia I, et al. Updated clinical classification of pulmonary hypertension. J Am Coll Cardiol 2013;62(suppl 25):D34-D41

13 Renapurkar RD, Shrikanthan S, Heresi GA, Lau CT, Gopalan D. Imaging in chronic thromboembolic pulmonary hypertension. J Thorac Imaging 2017;32(2):71-88

14 Tan RT, Kuzo R, Goodman LR, Siegel R, Haasler GB, Presberg KW; Medical College of Wisconsin Lung Transplant Group. Utility of CT scan evaluation for predicting pulmonary hypertension in patients with parenchymal lung disease. Chest 1998;113(5):1250-1256

15 Ng CS, Wells AU, Padley SP. A CT sign of chronic pulmonary arterial hypertension: the ratio of main pulmonary artery to aortic diameter. J Thorac Imaging 1999;14(4):270-278

16 Revel M-P, Faivre J-B, Remy-Jardin M, Delannoy-Deken V, Duhamel A, Remy J. Pulmonary hypertension: ECG-gated 64-section CT angiographic evaluation of new functional parameters as diagnostic criteria. Radiology 2009;250(2):558-566

17 Mesquita SM, Castro CR, Ikari NM, Oliveira SA, Lopes AA. Likelihood of left main coronary artery compression based on pulmonary trunk diameter in patients with pulmonary hypertension. Am J Med 2004;116(6):369-374

18 Wittram C, Kalra MK, Maher MM, Greenfield A, McLoud TC, Shepard J-AO. Acute and chronic pulmonary emboli: angiography-CT correlation. AJR Am J Roentgenol 2006;186(6, suppl 2) :S421-S429

19 Remy-Jardin M, Duhamel A, Deken V, Bouaziz N, Dumont P, Remy J. Systemic collateral supply in patients with chronic thromboembolic and primary pulmonary hypertension: assessment with multi-detector row helical CT angiography. Radiology 2005;235(1):274-281

20 Nishiyama KH, Saboo SS, Tanabe Y, Jasinowodolinski D, Landay MJ, Kay FU. Chronic pulmonary embolism: diagnosis. Cardiovasc Diagn Ther 2018;8(3):253-271

21 Ryan R, Abbara S, Colen RR, et al. Cardiac valve disease: spectrum of findings on cardiac 64-MDCT. AJR Am J Roentgenol 2008;190(5):W294-303

22 Waller BF, Howard J, Fess S. Pathology of pulmonic valve stenosis and pure regurgitation. Clin Cardiol 1995;18(1):45-50

23 Volpe P, Paladini D, Marasini M, et al. Characteristics, associations and outcome of absent pulmonary valve syndrome in the fetus. Ultrasound Obstet Gynecol 2004;24(6):623-628

24 Bhupali AN, Patankar KB, Prasad S, Patil JK, Tamhane A. Absent pulmonary valve syndrome with tetralogy of Fallot detected at an early gestational age of 27 weeks-a case report. Indian Heart J 2013;65(2):191-193 
25 Botney MD. Role of hemodynamics in pulmonary vascular remodeling: implications for primary pulmonary hypertension. Am J Respir Crit Care Med 1999;159(2):361-364

26 Frid MG, Li M, Gnanasekharan M, et al. Sustained hypoxia leads to the emergence of cells with enhanced growth, migratory, and promitogenic potentials within the distal pulmonary artery wall. Am J Physiol Lung Cell Mol Physiol 2009;297(6):L1059-L1072

27 Guillaume B, Vendrell A, Stefanovic X, Thony F, Ferretti GR. Acquired pulmonary artery pseudoaneurysms: a pictorial review. Br J Radiol 2017;90(1073):20160783

28 Ketchum ES, Zamanian RT, Fleischmann D. CT angiography of pulmonary artery aneurysms in Hughes-Stovin syndrome. AJR Am J Roentgenol 2005;185(2):330-332

29 Nollen GJ, van Schijndel KE, Timmermans J, et al. Pulmonary artery root dilatation in Marfan syndrome: quantitative assessment of an unknown criterion. Heart 2002;87(5):470-471

30 Meester JAN, Verstraeten A, Schepers D. Alaerts M, Van Laer L, Loeys BL. Differences in manifestations of Marfan syndrome, Ehlers-Danlos syndrome, and Loeys-Dietz syndrome. Ann Cardiothorac Surg 2017;6(6):582-594

31 Kreibich M, Siepe M, Kroll J, Höhn R, Grohmann J, Beyersdorf F. Aneurysms of the pulmonary artery. Circulation 2015;131(3):310-316

32 Lee W-K, Mossop PJ, Little AF, et al. Infected (mycotic) aneurysms: spectrum of imaging appearances and management. Radiographics 2008;28(7):1853-1868

33 Cajigas-Loyola SC, Miller RL, Spieler B, Carbonella G. Mycotic pulmonary artery aneurysm mimicking a Rasmussen aneurysm. Ochsner J 2018;18(1):104-107

34 Sapra R, Sharma G, Minz AK. Rasmussen's aneurysm: a rare and forgotten cause of hemoptysis. Indian Heart J 2015;67(suppl 3) :S53-S56

35 Sharma A, Kumar S, Jagia P. Pulmonary artery pseudoaneurysm in hyper-IgE syndrome: rare complication with successful endovascular management. Vasc Endovascular Surg 2018;52(5):375-377

36 Zhu G, Pu X, Guo H, Huang X, Chen D, Gan H. Clinical features of pulmonary artery sarcoma: a report of three cases. Exp Ther Med 2016;12(2):1201-1205

37 Yi CA, Lee KS, Choe YH, Han D, Kwon OJ, Kim S. Computed tomography in pulmonary artery sarcoma: distinguishing features from pulmonary embolic disease. J Comput Assist Tomogr 2004;28(1):34-39

38 Chong S, Kim TS, Kim B-T, Cho EY, Kim J. Pulmonary artery sarcoma mimicking pulmonary thromboembolism: integrated FDG PET/CT. AJR Am J Roentgenol 2007;188(6):1691-1693

39 You CK, Whatley GS. Swan-Ganz catheter-induced pulmonary artery pseudoaneurysm: a case of complete resolution without intervention. Can J Surg 1994;37(5):420-424

40 Goel S, Kumar A, Gamanagatti S, Gupta A. Spontaneous resolution of post-traumatic pulmonary artery pseudoaneurysm: report of two cases. Lung India 2013;30(3):203-205
41 Rai VK, Malireddy K, Dearmond D, Myers J, Dent DL. Traumatic pseudoaneurysm of the pulmonary artery. J Trauma 2010;69(3):730

42 Kirton OC, Varon AJ, Henry RP, Civetta JM. Flow-directed, pulmonary artery catheter-induced pseudoaneurysm: urgent diagnosis and endovascular obliteration. Crit Care Med 1992;20(8):1178-1180

43 Ferretti GR, Thony F, Link KM, et al. False aneurysm of the pulmonary artery induced by a Swan-Ganz catheter: clinical presentation and radiologic management. AJR Am J Roentgenol 1996;167(4):941-945

44 Poplausky MR, Rozenblit G, Rundback JH, Crea G, Maddineni S, Leonardo R. Swan-Ganz catheter-induced pulmonary artery pseudoaneurysm formation: three case reports and a review of the literature. Chest 2001;120(6):2105-2111

45 Barash PG, Nardi D, Hammond G, et al. Catheter-induced pulmonary artery perforation. Mechanisms, management, and modifications. J Thorac Cardiovasc Surg 1981;82(1):5-12

46 McDaniel DD, Stone JG, Faltas AN, et al. Catheter-induced pulmonary artery hemorrhage. Diagnosis and management in cardiac operations. J Thorac Cardiovasc Surg 1981;82(1):1-4

47 Wunderbaldinger P, Bernhard C, Uffmann M, Kürkciyan I, Senbaklavaci O, Herold CJ. Acute pulmonary trunk dissection in a patient with primary pulmonary hypertension. J Comput Assist Tomogr 2000;24(1):92-95

48 Florczyk M, Wieteska M, Kurzyna M, et al. Acute and chronic dissection of pulmonary artery: new challenges in pulmonary arterial hypertension? Pulm Circ 2018;8(2):2045893217749114

49 Senbaklavaci O, Kaneko Y, Bartunek A, et al. Rupture and dissection in pulmonary artery aneurysms: incidence, cause, and treatment-review and case report. J Thorac Cardiovasc Surg 2001;121(5):1006-1008

50 Savic V, Rahmanian LB, Renner T, et al. Acute pulmonary artery dissection with an ongoing extrinsic myocardial infarction. J Am Coll Cardiol Case Rep 2019;1(3):376-380

51 Neimatallah MA, Hassan W, Moursi M, Al Kadhi Y. CT findings of pulmonary artery dissection. BrJRadiol 2007;80(951):e61-e63

52 Abbott ME, Atlas of Congenital Cardiac Disease: New Edition. Montreal: MQUP; 2006

53 Balboni FA, Lopresti J. Congenital idiopathic dilatation of the pulmonary artery in children. A report of seven cases. Heart Cent Bull (Roslyn 1961;17:1-21

54 Malviya A, Jha PK, Kalita JP, Saikia MK, Mishra A. Idiopathic dilatation of pulmonary artery: a review. Indian Heart J 2017;69(1):119-124

55 Deb SJ, Zehr KJ, Shields RC. Idiopathic pulmonary artery aneurysm. Ann Thorac Surg 2005;80(4):1500-1502

56 Theodoropoulos P, Ziganshin BA, Tranquilli M, Elefteriades JA. Pulmonary artery aneurysms: four case reports and literature review. Int J Angiol 2013;22(3):143-148

57 Park HS, Chamarthy MR, Lamus D, Saboo SS, Sutphin PD, Kalva SP. Pulmonary artery aneurysms: diagnosis \& endovascular therapy. Cardiovasc Diagn Ther 2018;8(3):350-361 